\title{
Comparative Evolutionary Psychology of Sperm Competition
}

\author{
Todd K. Shackelford and Aaron T. Goetz \\ Florida Atlantic University
}

\begin{abstract}
A comparative evolutionary psychological perspective predicts that species that recurrently faced similar adaptive problems may have evolved similar psychological mechanisms to solve these problems. Sperm competition provides an arena in which to assess the heuristic value of such a comparative evolutionary perspective. The sperm competition that results from female infidelity and polyandry presents a similar class of adaptive problems for individuals across many species. The authors first describe mechanisms of sperm competition in insects and in birds. They suggest that the adaptive problems and evolved solutions in these species provide insight into human anatomy, physiology, psychology, and behavior. The authors then review recent theoretical and empirical arguments for the existence of sperm competition in humans and discuss proposed adaptations in humans that have analogs in insects or birds. The authors conclude by highlighting the heuristic value of a comparative evolutionary psychological approach in this field.
\end{abstract}

Keywords: sperm competition, evolutionary psychology, comparative psychology, sexual selection, cuckoldry

A comparative evolutionary perspective offers a number of benefits. Such an approach presents a way of characterizing and understanding the similarities and differences in the adaptive problems and adaptive solutions of different species (Daly \& Wilson, 1999; Harvey \& Pagel, 1991). Similar selection pressures (e.g., habitat, diet, mating system) can cause different species that are not closely related to evolve similar solutions. Here, convergent evolution, as opposed to common ancestry, is responsible for the evolution of similar mechanisms (called analogs). Convergent evolution and analogy are typically used in reference to morphology, but can also be used to describe analogous physiology, psychology, and behavior.

Using a comparative evolutionary perspective, the study of nonhuman animal psychology and behavior can shed light on human psychology and behavior. Parental investment theory (Trivers, 1972), for example, has been successful in explaining between-sex differences in mating strategies and reproductive behaviors in a number of species, including humans. Analogously, sperm competition theory has generated a wealth of information about the reproductive behaviors of a number of species (for reviews, see Birkhead \& Møller, 1998; Shackelford, Pound, \& Goetz, 2005; Shackelford \& Pound, 2006; Simmons, 2001). In this article, we present a comparative approach to evolutionary psychology, demonstrating that an understanding of the adaptive problems, evolved psychologies, and manifest behaviors of one species can offer insight into the evolved psychologies and manifest behaviors of other species. The focus of this article is on cross-species similarities, although a comparative evolutionary

Todd K. Shackelford and Aaron T. Goetz, Department of Psychology, Florida Atlantic University.

The authors contributed equally to this article.

Correspondence concerning this article should be addressed to Todd K. Shackelford, Department of Psychology, Florida Atlantic University, 2912 College Avenue, Davie, FL 33314. Email: tshackel@fau.edu perspective also can be valuable in identifying cross-species differences (e.g., Dixson, 1998; see also Shackelford \& LeBlanc, 2001).

Along with the benefits of a comparative evolutionary perspective, a number of difficulties appear (see Daly \& Wilson, 1999). For example, apparently similar adaptive problems confronted by different species are not always solved by the same evolved mechanisms. Moreover, there are no rigid guidelines for judging the similarity or dissimilarity of behaviors manifested by different species. In addition, there are no widely agreed-upon guidelines for identifying whether selection pressures across different species represent similar adaptive problems confronted by these different species or different adaptive problems that share qualitative features.

Our goal in this article is not to resolve these and other difficulties associated with adopting a comparative evolutionary perspective but, these difficulties notwithstanding, to demonstrate that a comparative evolutionary perspective can offer some insight into the evolved mechanisms and manifest behaviors of different species that have recurrently confronted similar classes of adaptive problems. Of key interest in this article is the value of a comparative evolutionary perspective for gaining a better understanding of human psychology and behavior. Specifically, we argue in this article that the adaptive problems associated with sperm competition faced by some species of insects and many species of birds also have been faced by humans, and that these shared adaptive problems may have selected for similar adaptive solutions in insects, birds, and humans (and see Shackelford \& LeBlanc, 2001).

\section{Overview of Sperm Competition}

Sexual selection is the process that favors an increase in the frequency of alleles associated directly with reproduction (Andersson, 1994; Darwin, 1871). Sexual selection includes the two components of intrasexual competition (competition between members of the same sex for sexual access to members of the other sex) and 
intersexual selection (differential mate choice of members of the other sex). Because members of the sex that invests more in offspring are more selective with whom they mate (Trivers, 1972), sexual selection typically involves males competing for mates and females choosing among them. Studies of sexual selection have generally focused on these processes, but beginning in the 1970s, researchers recognized that sexual selection also involves processes that occur after the initiation of copulation. Thus, an alternative way of thinking about sexual selection is that there may not only be a competition between males for mates, but a competition between males for fertilizations.

Sperm competition is the inevitable consequence of males competing for fertilizations. If females mate in a way that concurrently places sperm from two or more males in the reproductive tract of a female, this generates several selection pressures on males. If these selection pressures are recurrent throughout a species' evolutionary history, males will evolve tactics to aid their sperm in out-competing rivals' sperm for fertilizations. These tactics may take the form of anatomical, physiological, and psychological adaptations.

Although important contributions to sperm competition theory have been made by researchers studying many different species, the initial theoretical formulation was based on observations of three species of flies (Parker, 1970). Parker's discovery of sperm competition in insects was facilitated by the fact that many insects can store sperm for long periods of time in specialized organs, coupled with the ease with which females can be observed in multiple matings. Parker's interest in game theory led him to consider the potential for an evolutionary arms race. On one hand, there would have been selection pressures for males to remove from a female the sperm deposited by previous suitors. On the other hand, selection would have favored those males that were able to prevent removal of their own sperm. Parker noted that the final male to inseminate a female typically fertilized $80 \%$ of the eggs. Investing more time and energy into copulating with a single female could produce a fertilization rate of $100 \%$. Observations of male behaviors led Parker to conclude that males maximized their offspring production not by monopolizing a single female, but by mating with multiple females. These observations and theoretical considerations formed the basis of sperm competition theory (Parker, 1970; for theoretical extensions and refinements, see Parker, 1990a, 1990b, 1993, 1998).

Sperm competition provides a good "test case" for the heuristic value of a comparative evolutionary psychological perspective (Shackelford \& LeBlanc, 2001). There is a wealth of information about sperm competition in many nonhuman animals, notably in insects and in birds (see, e.g., Birkhead \& Møller, 1992, 1998; Simmons, 2001). In addition, there is a growing body of work suggesting that sperm competition was an important selective force in shaping modern human psychology, physiology, anatomy, and behavior (Baker \& Bellis, 1993a; Gallup \& Burch, in press; Gallup, Burch, \& Berens Mitchell, in press; Gallup et al., 2003; Goetz \& Shackelford, in press; Goetz et al., 2005; Kilgallon \& Simmons, 2005; Klusmann, 2002; Pound, 2002; Shackelford, 2003; Shackelford, Goetz, Guta, \& Schmitt, in press; Shackelford et al., 2002; Shackelford \& Pound, 2006; Shackelford, Pound, \& Goetz, 2005; Shackelford, Pound, Goetz, \& LaMunyon, 2005; Smith, 1984). One approach for furthering the understanding of human sexuality is to apply a comparative evolutionary psycho- logical perspective to the study of sperm competition. Examining human sexual psychology and behavior using a comparative evolutionary psychological approach to sperm competition affords a better understanding of the similarities and differences between humans and other sexually reproducing species.

\section{Sperm Competition in Insects and in Birds}

The first examination of sperm competition was in insects (Parker, 1970). Insects provide a model of sperm competition that is applicable to a number of species. Sperm competition is intense in several insect species because females participate in multiple matings with different males in a short period of time (see Simmons, 2001, for a review). Males of these insects, like males of other species, benefit by avoiding sperm competition (however, a male of a species that forms long-term pair bonds would benefit from entering sperm competition if his in-pair partner recently copulated with another male). Birds also have been studied extensively within the context of sperm competition. There are similarities between the mechanisms of sperm competition documented in birds and the mechanisms of sperm competition documented in insects. For example, the males of many species of birds and insects recurrently had to solve problems of avoiding sperm competition.

Sperm competition mechanisms in birds also have important implications for the study of human sperm competition. Not only have avian males and human males faced many of the same adaptive problems with respect to avoiding sperm competition, but it is also the case that the majority of bird species engage in social monogamy - the mating system characteristic of humans (Shackelford, Pound, \& Goetz, 2005; Baker \& Bellis, 1995; Birkhead \& Møller, 1992; Smith, 1984). Social monogamy is a mating system in which a male and a female form a long-term pair bond but also pursue extrapair copulations. Human males and the males of many bird species invest substantially in offspring, which places these males at risk of cuckoldry-investing in genetically unrelated offspring. These and other similarities suggest the possibility of discovering similar mating behaviors, motivated by similar evolved psychologies, in insects, in birds, and in humans.

The following sections discuss several adaptations that insects and birds have evolved in response to an evolutionary history of sperm competition. We limit our discussion of adaptations to testis size, mate guarding, sperm displacement, frequent in-pair copulation, ejaculate adjustment, and forced in-pair copulation. These adaptations were selected for discussion instead of others because each is well documented in insects or in birds and each has a clear human analog.

Testis size. In species with internal fertilization, the outcome of sperm competition (notwithstanding mating order effects) depends on a "lottery" principle: a particular male can increase the probability of siring a female's offspring by inseminating more sperm (e.g., Parker, 1970, 1990a). Accordingly, investment in sperm production has been shown to be greater in species with high levels of sperm competition. In insects, testis size relative to body size (an index of investment in sperm production) is correlated positively with the frequency with which females engage in polyandrous matings (Gage, 1994). For example, experimentally exposing yellow dung flies to high levels of sperm competition can significantly increase testis size after just 10 generations (Hosken 
\& Ward, 2001). Likewise in birds, species involved in more intense sperm competition have larger testes than related species for which sperm competition is less intense (Møller, 1988; Møller \& Briskie, 1995).

Mate guarding. Some male insects are equipped with mechanisms that are designed to prevent the opportunity for future sperm competition (Thornhill \& Alcock, 1983). These "mate guarding" mechanisms can be classified as proximate or remote. Proximate mate guarding involves a male staying within close physical distance of the female with whom he has recently copulated (Tsubaki, Siva-Jothy, \& Ono, 1994). Remote mate guarding involves tactics designed to aid the male in avoiding competition with sperm from rival males when he is not physically present with his partner to do this guarding himself. In insects, for example, a copulatory plug is sometimes formed after copulation (Drummond, 1984). This plug is the result of chemical reactions between the seminal fluid and oxygen in the air. The plug blocks the female's genital orifice and thereby prevents future insemination by other males. Another form of remote mate guarding involves the postcopulatory release of a substance in the seminal fluid that reduces the receptivity of the female to rival males (Chen et al., 1988; Thornhill, 1976).

In birds, male mate guarding includes close following and surveillance of the female (Birkhead, 1979; Brylawski \& Whittingham, 2004). It was once thought that males guard their mates as a result of the pair bond that they form (Birkhead \& Møller, 1992), but sperm competition theory offers a clearer understanding of the underlying mechanisms and processes. As males spend greater amounts of time away from their partners, the incidence of female extrapair copulation increases (Alatalo, Gottlander, \& Lundberg, 1987). Accordingly, avian males adjust the intensity with which they guard their partners so that this mate guarding is most intense when their partners are at peak fertility (Møller, 1987). But there are costs to mate guarding. Avian males engaged in mate guarding expend time and energy that could be used to locate food or to acquire additional mates, for example. And although an effective tactic in many species, females are sometimes able to circumvent their partners' mate guarding and obtain extrapair copulations (Kempenaers, Verheyen, \& Dhondt, 1997). We acknowledge that not all forms of mate guarding are adaptations to sperm competition. Copulatory plugs, for example, evolve in response to sperm competition, but other forms of mate guarding, such as female surveillance, can evolve in the absence of sperm competition.

Sperm displacement. Features of the penis may have evolved in response to the selective pressures of sperm competition. Waage (1979) was the first to study sperm displacement. He documented, for example, that the penis of the damselfly is equipped with spines that are able to remove up to $99 \%$ of the sperm stored in a female (Waage, 1979). Sperm displacement is not limited to damselflies; this sperm competition mechanism is apparent in many insect species. The penis of the tree cricket, for example, is structurally designed to remove rival sperm prior to insemination of the male's own ejaculate (Ono, Siva-Jothy, \& Kato, 1989; see also Gage, 1992). Although only 3\% of bird species possess a penis (Briskie \& Montgomerie, 1997), for these species the penis often has features designed to displace rival sperm. Spines, ridges, and knobs on the penis of some waterfowl are positioned in a way to displace rival sperm and these protuberances are larger in species for which the intensity of sperm competition is greater (Coker,
McKinney, Hays, Briggs, \& Cheng, 2002; McCracken, Wilson, McCracken, \& Johnson, 2001; cf. Briskie \& Montgomerie, 1997).

Frequent in-pair copulation. Frequent in-pair copulation in insects can serve as a sperm competition tactic by placing large numbers of sperm in competition with rival sperm for access to ova. Burying beetles, field crickets, and water bugs, for example, use frequent in-pair copulation as an effective sperm competition tactic (Muller \& Eggert, 1989; Simmons, 1987; Smith, 1979). In birds, frequent in-pair copulation is a well-documented sperm competition tactic (Birkhead, Atkin, \& Møller, 1987; McKinney, Cheng, \& Bruggers, 1984). In-pair copulation frequency increases with greater risk of female extrapair copulation in many bird species (Møller, 1985; Mougeot, Arroyo, \& Bretagnolle, 2001). A male osprey, for example, copulates as many as 10 times per day with his partner when she is at peak fertility - just prior to egg laying. Copulatory frequency approaches zero after the first egg is laid, when her fertility is at a minimum (Birkhead \& Lessels, 1988). These behavioral patterns suggest that these birds are sensitive to the potential costs of sperm competition and that frequent in-pair copulations function to reduce the likelihood of incurring these costs.

Ejaculate adjustment. One of the first hypotheses generated by sperm competition theory was that males will deliver more sperm when the risk of sperm competition is high (Parker, 1982). Within species, males are predicted to adjust sperm number in accord with the risk of sperm competition (Wedell, Gage, \& Parker, 2002). Accordingly, experimental methods have demonstrated that males of many insect species are capable of adjusting the number of sperm they deliver in response to cues of sperm competition risk (e.g., Cook \& Wedell, 1996; Gage \& Baker, 1991; Simmons \& Siva-Jothy, 1998). Some bird species also have been shown to adjust the number of sperm delivered in contexts of sperm competition. The fowl, for example, adjusts the number of sperm delivered according to the level of female promiscuity, and the sand martin delivers a larger number of sperm in the presence of rival males (Nicholls, Burke, \& Birkhead, 2001; Pizzari, Cornwallis, Løvlie, Jakobsson, \& Birkhead, 2003).

Forced in-pair copulation. In many bird species, forced inpair copulation occurs immediately after a female partner's extrapair copulations, territorial intrusions by rival males, and female absence (e.g., Barash, 1977; McKinney \& Stolen, 1982). Forced in-pair copulation following observed or suspected female extrapair copulation is often interpreted as a sperm competition tactic because the male's forced in-pair copulation functions to place his sperm in competition with sperm from an extrapair male (Cheng, Burns, \& McKinney, 1983). Forced in-pair copulation has not been documented unequivocally in insects (see Simmons, 2001).

The preceding sections introduced key physiological and behavioral mechanisms and tactics of sperm competition in birds and in insects. We presented information that provides a basis for comparing the adaptive problems and evolved solutions in insects and in birds to those in humans. The similarities in the mating system and parenting system of some birds and humans may have generated similar adaptive problems for these species in the domain of sperm competition. The next sections review theoretical arguments and empirical evidence for the existence of human sperm competition (and see Shackelford, Pound, \& Goetz 2005; Shackelford \& Pound, 2006). 


\section{Sperm Competition as an Adaptive Problem in Humans}

Smith (1984) presented theoretical arguments for the existence of sperm competition in humans. Sperm competition in humans requires that a woman copulates with more than one man within roughly a 5-day period, although some have argued for a more conservative estimate (e.g., Gallup et al., in press). Smith outlined several contexts in which sperm from two or more men might concurrently occupy the reproductive tract of a woman. Prostitution, communal sex (e.g., wife-swapping and orgies), courtship (i.e., short-term matings), rape, and female infidelity are contexts that can place the sperm of different men into competition. Prostitution, communal sex, and courtship are relatively rare and probably did not represent a recurrent context over the evolutionary history of humans in which sperm competition could act as a selective force (Smith, 1984).

Rape of females by males, however, probably was a recurrent feature of human evolutionary history (Lalumière, Harris, Quinsey, \& Rice, 2005; Smith, 1984; Thornhill \& Palmer, 2000). Despite cultural institutions that punish and discourage rape, rape of women by men is universal across cultures (see Lalumière et al., 2005 , for a review). There also is a strong association between rape and war, a key feature of our evolutionary past (Gottschall, 2004; Thornhill \& Palmer, 2000). These reports suggest that rape could have provided a recurrent context for sperm competition to act as a selection pressure on humans.

Female infidelity, however, is likely to have been the most common context for the concurrent presence of sperm from two or more men in the reproductive tract of a woman (Smith, 1984). Estimates of extrapair copulations in terms of marital infidelity rates range from $15 \%$ to $50 \%$ for women (Laumann, Gagnon, Michael, \& Michaels, 1994; Simmons, Firman, Rhodes, \& Peters, 2004). Moreover, the ubiquity and power of male sexual jealousy provides evidence of an evolutionary history of female infidelity and, therefore, sperm competition (e.g., Buss, Larsen, Westen, \& Semmelroth, 1992; Daly, Wilson, \& Weghorst, 1982; Symons, 1979). Finally, recent research has identified several anatomical, physiological, psychological, and behavioral features (reviewed below) that are parsimoniously explained if female infidelity occurred with sufficient frequency throughout human evolutionary history.

\section{Empirical Evidence for Human Sperm Competition}

The following sections discuss several adaptations humans may have evolved in response to an evolutionary history of sperm competition. Again, we limit our discussion of these adaptations to testis size, mate guarding, semen displacement, frequent in-pair copulation, ejaculate adjustment, and forced in-pair copulation, because each of these features have analogs in insects or in birds.

Testis size. Across a range of different animals, males have relatively larger testes in species with more intense sperm competition (e.g., Gomendio, Harcourt, \& Roldán, 1998; Harcourt, Harvey, Larson, \& Short, 1981). Because larger testes produce more sperm, males can better compete by emitting more sperm. Among gorillas, for instance, female promiscuity and sperm competition are rare and the male gorilla's testes are relatively small, comprising just $0.03 \%$ of body weight. Chimpanzees, in contrast, are highly promiscuous (females may copulate 1,000 times for each pregnancy) and, accordingly, males have relatively large testes, comprising $0.30 \%$ of body weight. The size of human testes fall between these two extremes at $0.08 \%$ of body weight, suggesting intermediate levels of female promiscuity and sperm competition in our evolutionary past (Gomendio et al., 1998; Harcourt et al., 1981; Short, 1979; Smith, 1984).

Mate guarding. Like insect and bird species, human males guard their mates to maintain their partner's exclusive involvement with them. Buss (1988) identified specific mate guarding behaviors such as vigilance (e.g., dropping by unexpectedly to check up on a partner), concealment of mate (e.g., taking a partner away from a social gathering where other men are present), and monopolization of time (e.g., insisting that a partner stay home rather than go out). These mate guarding behaviors vary in ways that suggest they have evolved as paternity guards. For example, a man guards his partner more intensely when she is of greater reproductive value (as indexed by her youth and attractiveness) and when the perceived probability of her extrapair copulation is greater (Buss \& Shackelford, 1997). In addition, men who are mated to women who are more likely to engage in extrapair copulation guard their partners more intensely (Goetz et al., 2005) and men guard their partner more intensely near ovulation-a time when an extrapair copulation would be most costly for the in-pair male (Gangestad, Thornhill, \& Garver, 2002).

Semen displacement. The human male's penis does not possess barbs and spines for removing rival sperm, but recent empirical evidence suggests that the human penis may have evolved to function, in part, as a semen displacement device. Using artificial genitals and simulated semen, Gallup et al. (2003) tested the hypothesis that the human penis is designed to displace semen deposited by other men in the reproductive tract of a woman. The results indicated that artificial phalluses that had a glans and coronal ridge that approximated a human penis displaced significantly more simulated semen than did a phallus that did not have such features. When the penis is inserted into the vagina, the frenulum of the coronal ridge makes semen displacement possible by allowing semen to flow back under the penis alongside the frenulum and collect on the anterior of the shaft behind the coronal ridge. Displacement of simulated semen occurred when a phallus was inserted at least $75 \%$ of its length into the artificial vagina (Gallup et al., 2003).

That the penis must reach an adequate depth before semen is displaced suggests that successfully displacing rival semen may require specific copulatory behaviors. Following allegations of female infidelity or separation from their partners (contexts in which the likelihood of rival semen being present is relatively greater), both men and women report that the man thrusted his penis more deeply and more quickly into the vagina at the couple's next copulation (Gallup et al., 2003), behaviors likely to increase semen displacement. In an independent study, Goetz et al. (2005) investigated men's copulatory behaviors when under a high risk of sperm competition. Men mated to women who placed them at a high risk of sperm competition were more likely to use specific copulatory behaviors arguably designed to displace rival semen (e.g., number of thrusts, deepest thrust, average depth of thrusts, and duration of sexual intercourse) than were men mated to women who did not place them at high risk of sperm competition (Goetz et al., 2005). Subsequent studies have provided additional 
support for the semen displacement hypothesis (Gallup \& Burch, 2004, "in press; Gallup, Burch, \& Berens Mitchell, 2005).

Frequent in-pair copulation. Like insects and birds, human males may use frequent in-pair copulations as a sperm competition tactic (Shackelford et al., in press). Baker and Bellis (1993a) developed a model of strategic partitioning of sperm in which men replace in their partner's reproductive tract sperm lost through death and phagocytosis, and thereby increase the total functional sperm population in her reproductive tract. Frequent in-pair copulation as a sperm competition tactic may help to explain why men, but not women, continue to be interested in copulating with their partner over the duration of a mateship (Klusmann, 2002). Although men report that their sexual satisfaction and the quality of marital sex declines with the duration of the mateship (Chien, 2003; Klusmann, 2002), men's desire for sexual intercourse with their partner does not decline with the duration of the mateship.

Ejaculate adjustment. A key hypothesis derived from sperm competition theory is that males will adjust the number of sperm they inseminate as a function of the risk that their sperm will encounter competition from the sperm of other males (Parker, 1982). Studying humans, Baker and Bellis (1989, 1993a, 1995) documented a negative relationship between the proportion of time a couple has spent together since their last copulation and the number of sperm ejaculated at the couple's next copulation. As the amount of time a couple spends together since their last copulation decreases, there is a predictable increase in the probability that the man's partner has been inseminated by another male (Baker \& Bellis, 1995; Shackelford et al., 2002). Additional regression analyses documented that the proportion of time a couple spent together since their last copulation is a significant predictor of sperm number ejaculated at the couple's next copulation, but not at the man's next masturbation (Baker \& Bellis, 1989, 1995). Inseminating more sperm following a separation may function to outnumber or "flush out" sperm from rival men that may be present in the reproductive tract of the woman (Baker \& Bellis, 1995; Parker, 1970, 1982).

Inspired by Baker and Bellis's (1993a) demonstration of male physiological adaptations to competition, Shackelford et al. (2002) documented that human male psychology may include psychological adaptations to decrease the likelihood that a rival man's sperm will fertilize a partner's egg(s). For example, men who spent a greater (relative to men who spent a lesser) proportion of time apart from their partner since the couple's last copulation rated their partners as more attractive and reported greater interest in copulating with their partners. These perceptual changes may motivate men to copulate as soon as possible with their partner, thereby entering their sperm into competition with any rival sperm that may be present in her reproductive tract.

Forced in-pair copulation. Noting that instances of forced in-pair copulation followed extrapair copulations in waterfowl and documentation that forced in-pair copulation in humans often followed accusations of female infidelity (e.g., Finkelhor \& Yllo, 1985; Russell, 1982), Wilson and Daly (1992) hypothesized that sexual coercion in response to cues of a partner's sexual infidelity might function in humans to introduce a man's sperm into his partner's reproductive tract at a time when there is a high risk of extrapair paternity. Goetz and Shackelford (in press) tested and found empirical support for this hypothesis. In two studies, Goetz and Shackelford found that men's sexual coercion in the context of an intimate relationship was related positively to his partner's infidelities. According to men's self-reports and women's partnerreports, men who used more sexual coercion in their relationship are mated to women who had been or were likely to be unfaithful.

Less empirical research has investigated the mechanisms of female psychology that may have been forged by an evolutionary history of sperm competition. The focus of this article was on male adaptations to sperm competition, although we acknowledge that if sperm competition was a recurrent feature of a species' evolutionary history, adaptations might be expected not only in males but also in females. It is possible, for example, that women can influence the outcome of any sperm competition that takes place within their reproductive tracts (Baker \& Bellis, 1993b, 1995; Gallup et al., in press; Thornhill, Gangestad, \& Comer, 1995; Shackelford et al., 2000). Given the methodological difficulties associated with studying female influences on sperm competition, it is not surprising that there has been less work investigating adaptations to sperm competition in females, in insects, birds, and mammals, including humans.

\section{Summary and Conclusion}

A comparative evolutionary psychological perspective predicts that species that recurrently faced similar adaptive problems may have evolved similar mechanisms to solve these problems. Sperm competition presents individuals of a variety of species with similar adaptive problems. Over the evolutionary history of these species, sperm competition was an integral component of sexual selection. We are not arguing that similarities across wide phylogenetic chasms (such as insects, birds, and humans) necessitate homologous mechanisms, but rather that similar mechanisms may be the products of convergent or independent evolution of solutions to similar adaptive problems (see, e.g., Burghardt, 2005). We reviewed the development of sperm competition theory and highlighted some of the evolved mechanisms in insects and birds that were identified in early sperm competition research. From a comparative evolutionary psychological perspective, it is predicted that the similarities in the adaptive problems recurrently faced by socially monogamous birds and humans sometimes led to similarities in the evolved psychologies of these species. Converging research suggests that this may be the case. Human females and the females of socially monogamous birds at least occasionally mate with multiple males and thereby generate sperm competition. Socially monogamous avian males and human males faced similar adaptive problems of preventing, correcting, and anticipating their female partner's infidelities. More generally, analogous evolved solutions to adaptive problems are evidenced by similar adaptations in insects, in birds, and in humans. Although we focused in the current article on insects, birds, and humans, sperm competition is an adaptive problem faced by many other species (for a review, see Birkhead \& Møller, 1998; for a recent review on snakes, see Rivas \& Burghardt, 2005). Readers interested in recent critical reviews of empirical and theoretical work on sperm competition in humans, including discussions of methodological limitations and important directions for future work, are directed to Shackelford, Pound, \& Goetz (2005) and to Shackelford and Pound (2006).

Early applications of a comparative evolutionary perspective were successful in identifying and explaining cross-species simi- 
larities and differences in mate selection and parenting behaviors (Trivers, 1972). A review of the sperm competition literature from a comparative evolutionary perspective suggests the possibility of a similarly successful cross-species analysis and integration. The adaptive problems of sperm competition and their evolved solutions in nonhuman species, notably insects and birds, provide a model for better understanding human sexual behaviors and psychology.

\section{References}

Alatalo, R. V., Gottlander, K., \& Lundberg, A. (1987). Extra-pair copulations and mate guarding in the polyterritorial pied flycatcher, Ficedula hypoleuca. Behaviour, 101, 139-155.

Andersson, M. B. (1994). Sexual selection. Princeton, NJ: Princeton University Press.

Baker, R. R., \& Bellis, M. A. (1989). Number of sperm in human ejaculates varies in accordance with sperm competition theory. Animal Behaviour, 37, 867-869.

Baker, R. R., \& Bellis, M. A. (1993a). Human sperm competition: Ejaculate adjustment by males and the function of masturbation. Animal Behaviour, 46, 861-885

Baker, R. R., \& Bellis, M. A. (1993b). Human sperm competition: Ejaculate manipulation by females and a function for the female orgasm. Animal Behaviour, 46, 887-909.

Baker, R. R., \& Bellis, M. A. (1995). Human sperm competition. London: Chapman \& Hall.

Barash, D. P. (1977). Sociobiology of rape in mallards (Anas platyrhynchos): Response of the mated male. Science, 197, 788-789.

Birkhead, T. R. (1979). Mate guarding in the magpie Pica pica. Animal Behaviour, 30, 277-283.

Birkhead, T. R., Atkin, L., Møller, A. P. (1987). Copulation behaviour of birds. Behaviour, 101, 101-138.

Birkhead, T. R., \& Lessels C. M. (1988). Copulation behavior of the osprey Pandion haliaetus. Animal Behaviour, 36, 1672-1682.

Birkhead, T. R., \& Møller, A. P. (1992). Sperm competition in birds. London: Academic Press.

Birkhead, T. R., \& Møller, A. P. (Eds.). (1998). Sperm competition and sexual selection. San Diego: Academic Press.

Briskie, J. V., \& Montgomerie, R. (1997). Sexual selection and the intromittent organ of birds. Journal of Avian Biology, 28, 78-86.

Brylawski, A. M. Z., \& Whittingham, L. A. (2004). An experimental study of mate guarding and paternity in house wrens. Animal Behaviour, 68, $1417-1424$.

Burghardt, G. M. (2005). The genesis of animal play. Cambridge, MA: MIT Press.

Buss, D. M. (1988). From vigilance to violence: Tactics of mate retention in American undergraduates. Ethology and Sociobiology, 9, 291-317.

Buss, D. M., Larsen, R. J., Westen, D., \& Semmelroth, J. (1992). Sex differences in jealousy: Evolution, physiology, and psychology. Psychological Science, 3, 251-255.

Buss, D. M., \& Shackelford, T. K. (1997). From vigilance to violence: Mate retention tactics in married couples. Journal of Personality and Social Psychology, 72, 346-361.

Chen, P. S., Stumm-Zollinger, E., Aigaki, T., Balmer, J., Bienz, M., \& Bohlen, P. (1988). A male accessory gland peptide that regulates reproductive behavior of female Drosophila melanogaster. Cell, 54, 291-298.

Cheng, K. M., Burns, J. T., \& McKinney, F. (1983). Forced copulation in captive mallards: III. Sperm competition. The Auk, 100, 302-310.

Chien, L. (2003). Does quality of marital sex decline with duration? Archives of Sexual Behavior, 32, 55-60.

Coker, C. R., McKinney, F., Hays, H., Briggs, S. V., \& Cheng, K. M. (2002). Intromittent organ morphology and testis size in relation to mating system in waterfowl. The Auk, 119, 403-413.
Cook, P. A., \& Wedell, N. (1996). Ejaculate dynamics in butterflies: A strategy for maximizing fertilization success? Proceedings of the Royal Society of London, 263, 1047-1051.

Daly, M., \& Wilson, M. (1999). Human evolutionary psychology and animal behaviour. Animal Behaviour, 57, 509-519.

Daly, M., Wilson, M., \& Weghorst, J. (1982). Male sexual jealousy. Ethology and Sociobiology, 3, 11-27.

Darwin, C. (1871). The descent of man, and selection in relation to sex. London: John Murray.

Dixson, A. F. (1998). Primate sexuality. New York: Oxford University Press.

Drummond, B. A. (1984). Multiple mating and sperm competition in the Lepidoptera. In R. L. Smith (Ed.), Sperm competition and the evolution of animal mating systems (pp. 547-572). New York: Academic Press.

Finkelhor, D., \& Yllo, K. (1985). License to rape. New York: Holt, Rinehart, and Winston.

Gage, M. J. G. (1992). Removal of rival sperm during copulation in a beetle, Tenebrio molitor. Animal Behaviour, 44, 587-589.

Gage, M. J. G. (1994). Associations between body-size, mating patterns, testis size, sperm lengths across butterflies. Proceedings of the Royal Society of London, 258, 247-254.

Gage, M. J. G., \& Baker, R. R. (1991). Ejaculate size varies with sociosexual situation in an insect. Ecological Entomology, 16, 331-337.

Gallup, G. G., \& Burch, R. L. (2004). Semen displacement as a sperm competition strategy in humans. Evolutionary Psychology, 2, 12-23.

Gallup, G. G., Burch, R. L., Zappieri, M. L., Parvez, R. A., Stockwell, M. L., \& Davis, J. A. (2003). The human penis as a semen displacement device. Evolution and Human Behavior, 24, 277-289.

Gallup G. G., \& Burch, R. L. (in press). The semen displacement hypothesis: Semen hydraulics, double mating, adaptations to self-semen displacement, and the ICP proclivity model. In S. M. Platek \& T. K. Shackelford (Eds.), Female infidelity and paternal uncertainty. New York: Cambridge University Press.

Gallup G. G., Burch, R. L., \& Berens Mitchell, T. J. (in press). Semen displacement as a sperm competition strategy: Multiple mating, selfsemen, displacement, and timing of in-pair copulations. Human Nature.

Gangestad, S. W., Thornhill, R., \& Garver, C. E. (2002). Changes in women's sexual interests and their partner's mate-retention tactics across the menstrual cycle: Evidence for shifting conflicts of interest. Proceedings of the Royal Society of London, 269, 975-982.

Goetz, A. T., Shackelford, T. K., Weekes-Shackelford, V. A., Euler, H. A., Hoier, S., Schmitt, D. P., \& LaMunyon, C. W. (2005). Mate retention, semen displacement, and human sperm competition: A preliminary investigation of tactics to prevent and correct female infidelity. Personality and Individual Differences, 38, 749-763.

Goetz, A. T., \& Shackelford T. K. (in press). Sexual coercion and forced in-pair copulation as sperm competition tactics in humans. Human Nature.

Gomendio, M., Harcourt, A. H., \& Roldán, E. R. S. (1998). Sperm competition in mammals. In T. R. Birkhead \& A. P. Møller (Eds.), Sperm competition and sexual selection (pp. 667-755). San Diego, CA: Academic Press.

Gottschall, J. (2004). Explaining wartime rape. Journal of Sex Research, 41, 129-136.

Harcourt, A. H., Harvey, P. H., Larson, S. G., \& Short, R. V. (1981, September 3). Testes weight, body weight, and breeding systems in primates. Nature, 293, 55-57.

Harvey, P. H., \& Pagel, M. D. (1991). The comparative method in evolutionary biology. Oxford, England: Oxford University Press.

Hosken, D. J., \& Ward, P. I. (2001). Experimental evidence for testis size evolution via sperm competition. Ecology Letters, 4, 10-13.

Kempenaers, B., Verheyen, G. R., \& Dhondt, A. A. (1997). Extrapair paternity in the blue tit (Parus caeruleus): Female mate choice, male 
characteristics, and offspring performance. Behavioral Ecology, 8, 481492.

Kilgallon, S. J., \& Simmons, L. W. (2005). Image content influences men's semen quality. Biology Letters, 1, 253-255.

Klusmann, D. (2002). Sexual motivation and the duration of partnership. Archives of Sexual Behavior, 31, 275-287.

Lalumière, M. L., Harris, G. T., Quinsey, V. L., \& Rice, M. E. (2005). The causes of rape: Understanding individual differences in male propensity for aggression. Washington, DC: American Psychological Association.

Laumann, E. O., Gagnon, J. H., Michael, R. T., \& Michaels, S. (1994). The social organization of sexuality. Chicago: University of Chicago Press.

Møller, A. P. (1985). Mixed reproductive strategy and mate guarding in a semi-colonial passerine, the swallow Hirundo rustica. Behavioral Ecology and Sociobiology, 17, 401-408.

Møller, A. P. (1987). Copulation behavior in the goshawk Accipiter gentilis. Animal Behaviour, 35, 755-763.

Møller, A. P. (1988). Testes size, ejaculate quality and sperm competition in birds. Biological Journal of the Linnean Society, 33, 273-283.

Møller, A. P., \& Briskie, J. V. (1995). Extra-pair paternity, sperm competition and the evolution of testes size in birds. Behavioral Ecology and Sociobiology, 36, 357-365.

McCracken, K. G., Wilson, R. E., McCracken, P. J., \& Johnson, K. P. (2001, September 13). Sexual selection: Are ducks impressed by drakes' display? Nature, 413, 128

McKinney, F., Cheng, K. M., \& Bruggers, D. J. (1984). Sperm competition in apparently monogamous birds. In R. L. Smith (Ed.), Sperm competition and evolution of animal mating systems (pp. 523-545). New York: Academic Press.

McKinney, F., \& Stolen, P. (1982). Extra-pair-bond courtship and forced copulation among captive green-winged teal (Anas crecca carolinensis). Animal Behaviour, 30, 461-474.

Mougeot, F., Arroyo, B. E., \& Bretagnolle, V. (2001). Decoy presentations as a means to manipulate the risk of extrapair copulation: An experimental study in a semicolonial raptor, the Montagu's harrier (Circus pygargus). Behavioral Ecology, 12, 1-7.

Muller, J. K., \& Eggert, A. K. (1989). Paternity assurance by "helpful" males: Adaptations to sperm competition in burying beetles. Behavioral Ecology and Sociobiology, 24, 245-249.

Nicholls, E. H., Burke, T., \& Birkhead, T. R. (2001). Ejaculate allocation by male sand martins, Riparia riparia. Proceedings of the Royal Society of London, 268, 1265-1270.

Ono, T., Siva-Jothy, M. T., \& Kato, A. (1989). Removal and subsequent ingestion of rival's semen during copulation in a tree cricket. Physiology and Entomology, 14, 195-202.

Parker, G. A. (1970). Sperm competition and its evolutionary consequences in the insects. Biological Reviews, 45, 525-567.

Parker, G. A. (1982). Why are there so many tiny sperm? Sperm competition and the maintenance of two sexes. Journal of Theoretical Biology, 96, 281-294.

Parker, G. A. (1990a). Sperm competition games: Raffles and roles. Proceedings of the Royal Society of London, 242, 120-126.

Parker, G. A. (1990b). Sperm competition games: Sneaks and extra-pair copulations. Proceedings of the Royal Society of London, 242, 127-133.

Parker, G. A. (1993). Sperm competition games: Sperm size and sperm number under adult control. Proceedings of the Royal Society of London, 253, 245-254.

Parker, G. A. (1998). Sperm competition and the evolution of ejaculates: Towards a theory base. In T. R. Birkhead \& A. P. Møller (Eds.), Sperm competition and sexual selection (pp. 3-54). San Diego: Academic Press.

Pizzari, T., Cornwallis, C. K., Løvlie, H., Jakobsson, S., \& Birkhead, T. R. (2003, November 6). Sophisticated sperm allocation in male fowl. Nature, 426, 70-74.
Pound, N. (2002). Male interest in visual cues of sperm competition risk. Evolution and Human Behavior, 23, 443-466.

Rivas, J. A., \& Burghardt, G. M. (2005). Snake mating systems, behavior, and evolution: The revisionary implications of recent findings. Journal of Comparative Psychology, 119, 447-454.

Russell, D. E. H. (1982). Rape in marriage. New York: Macmillan Press.

Shackelford, T. K. (2003). Preventing, correcting, and anticipating female infidelity: Three adaptive problems of sperm competition. Evolution and Cognition, 9, 90-96.

Shackelford, T. K., Goetz, A. T., Guta, F. E., \& Schmitt, D. P. (in press). Mate guarding and frequent in-pair copulation in humans: Concurrent or compensatory anti-cuckoldry tactics? Human Nature.

Shackelford, T. K., \& LeBlanc, G. J. (2001). Sperm competition in insects, birds, and humans: Insights from a comparative evolutionary perspective. Evolution and Cognition, 7, 194-202.

Shackelford, T. K., LeBlanc, G. J., Weekes-Shackelford, V. A., BleskeRechek, A. L., Euler, H. A., \& Hoier, S. (2002). Psychological adaptation to human sperm competition. Evolution and Human Behavior, 23 123-138.

Shackelford, T. K., \& Pound, N. (Eds.). (2006). Sperm competition in humans. New York: Springer.

Shackelford, T. K., Pound, N., \& Goetz, A. T. (2005). Psychological and physiological adaptation to human sperm competition. Review of General Psychology, 9, 228-248.

Shackelford, T. K., Pound, N., Goetz, A. T., \& LaMunyon, C. W. (2005). Female infidelity and sperm competition. In D. M. Buss (Ed.), The handbook of evolutionary psychology (pp. 372-393). Hoboken, NJ: Wiley.

Shackelford, T. K., Weekes-Shackelford, V. A., LeBlanc, G. J., Bleske, A. L., Euler, H. A., \& Hoier, S. (2000). Female coital orgasm and male attractiveness. Human Nature, 11, 299-306.

Short, R. V. (1979). Sexual selection and its component parts, somatic and genital selection, as illustrated by man and the great apes. Advances in the Study of Behavior, 9, 131-158.

Simmons, L. W. (1987). Sperm competition as a mechanism of female choice in the field cricket, Gryllus bimaculatus. Behavioral Ecology and Sociobiology, 21, 197-202.

Simmons, L. W. (2001). Sperm competition and its evolutionary consequences in the insects. Princeton, NJ: Princeton University Press.

Simmons, L. W., Firman, R. C., Rhodes, G., \& Peters, M. (2004). Human sperm competition: Testis size, sperm production, and rates of extrapair copulations. Animal Behaviour, 68, 297-302.

Simmons, L. W., \& Siva-Jothy, M. T. (1998). Sperm competition in insects: Mechanisms and the potential for selection. In T. R. Birkhead \& A. P. Møller (Eds.), Sperm competition and sexual selection (pp. 341434). San Diego: Academic Press.

Smith, R. L. (1979, September 7). Repeated copulation and sperm precedence: Paternity assurance for a male brooding waterbug. Science, 205 , 1029-1031.

Smith, R. L. (1984). Human sperm competition. In R. L. Smith (Ed.), Sperm competition and the evolution of animal mating systems (pp. 601-660). New York: Academic Press.

Symons, D. (1979). The evolution of human sexuality. New York: Oxford University Press.

Thornhill, R. (1976). Sexual selection and nuptial feeding behavior in Bittacus apocalis. American Naturalist, 110, 529-548.

Thornhill, R., \& Alcock, J. (1983). The evolution of insect mating systems. Cambridge, MA: Harvard University Press.

Thornhill, R., Gangestad, S. W., \& Comer, R. (1995). Human female orgasm and mate fluctuating asymmetry. Animal Behaviour, 50, 1601-1615.

Thornhill, R., \& Palmer, C. T. (2000). A natural history of rape. Cambridge, MA: MIT Press.

Trivers, R. L. (1972). Parental investment and sexual selection. In B 
Campbell (Ed.), Sexual selection and the descent of man 1871-1971 (pp. 136-179). Chicago: Aldine.

Tsubaki, Y., Siva-Jothy, M. T., \& Ono, T. (1994). Re-copulation and post-copulatory mate guarding increase immediate female reproductive output in the dragonfly, Nannophya pygmaea. Behavioral Ecology and Sociobiology, 35, 219-225.

Waage, J. K. (1979, March 2). Dual function of the damselfly penis: Sperm removal and transfer. Science, 203, 916-918.

Wedell, N., Gage, M. J. G., \& Parker, G. A. (2002). Sperm competition, male prudence and sperm-limited females. Trends in Ecology and Evolution, 17, 313-320.

Wilson, M., \& Daly, M. (1992). The man who mistook his wife for a chattel. In J. H. Barkow, L. Cosmides, \& J. Tooby (Eds.), The adapted mind (pp. 289-322). New York: Oxford University Press.

Received October 2, 2005 Revision received January 18, 2006 Accepted February, 1, 2006

\section{Members of Underrepresented Groups: Reviewers for Journal Manuscripts Wanted}

If you are interested in reviewing manuscripts for APA journals, the APA Publications and Communications Board would like to invite your participation. Manuscript reviewers are vital to the publications process. As a reviewer, you would gain valuable experience in publishing. The P\&C Board is particularly interested in encouraging members of underrepresented groups to participate more in this process.

If you are interested in reviewing manuscripts, please write to the address below. Please note the following important points:

- To be selected as a reviewer, you must have published articles in peer-reviewed journals. The experience of publishing provides a reviewer with the basis for preparing a thorough, objective review.

- To be selected, it is critical to be a regular reader of the five to six empirical journals that are most central to the area or journal for which you would like to review. Current knowledge of recently published research provides a reviewer with the knowledge base to evaluate a new submission within the context of existing research.

- To select the appropriate reviewers for each manuscript, the editor needs detailed information. Please include with your letter your vita. In the letter, please identify which APA journal(s) you are interested in, and describe your area of expertise. Be as specific as possible. For example, "social psychology" is not sufficient-you would need to specify "social cognition" or "attitude change" as well.

- Reviewing a manuscript takes time (1-4 hours per manuscript reviewed). If you are selected to review a manuscript, be prepared to invest the necessary time to evaluate the manuscript thoroughly.

Write to Journals Office, American Psychological Association, 750 First Street, NE, Washington, DC 20002-4242. 